\title{
Incidence of cranial ultrasound abnormalities in apparently well neonates on a postnatal ward: correlation with antenatal and perinatal factors and neurological status
}

\author{
Eugenio Mercuri, Lilly Dubowitz, Sara Paterson Brown, Frances Cowan
}

\begin{abstract}
Aim-To evaluate cranial ultrasonography and neurological examination in a cohort of infants regarded as normal; and to determine the prevalence of ultrasound abnormalities and any potential association with antenatal or perinatal factors or deviant neurological signs.
\end{abstract}

Methods-Cranial ultrasound findings and neurological status were evaluated in 177 newborns (gestational age 36.3 to 42 weeks), admitted to a postnatal ward directly after birth and regarded as normal by obstetric and paediatric staff. The age of the infants at the time of examination ranged between 6 and 48 hours. Ultrasound abnormalities were present in 35 of the 177 infants studied (20\%). Ischaemic lesions, such as periventricular and thalamic densities were the most common finding $(8 \%)$, followed by haemorrhagic lesions $(6 \%)$. The possible sequelae of antenatal haemorrhages, such as focal ventricular dilatation or choroid cysts, were present in $6 \%$. Abnormal ultrasound findings were not significantly associated with signs of perinatal distress, such as cardiotocographic abnormalities or passage of meconium. Abnormal ultrasound findings tended to be associated with antenatal problems, although this did not reach significance. Ultrasound abnormalities were strongly associated with deviant patterns on the neurological examination.

Conclusions-These results suggest that ultrasound abnormalities are more common than has been reported up to now. Lesions that could be ischaemic, such as flare densities, are seen even in the absence of any antenatal or perinatal risk factor.

Department of

Neonatal Medicine,

Hammersmith

Hospital,

London W12 OHN

Eugenio Mercuri

Lilly Dubowitz

Frances Cowan

Department of Obstetrics,

Queen Charlotte and

Chelsea Hospital,

Royal Postgraduate

Medical School,

London

S Paterson Brown

Correspondence to: Dr Eugenio Mercuri.

Accepted 20 April 1998
Keywords: cranial ultrasound; ischaemic lesions; perinatal distress; neurological abnormalities

Cranial ultrasonography is the most widely used technique for evaluating brain morphology and cerebral lesions in neonates. Serial ultrasound scans can identify not only the presence of lesions but also their type and extent. Ultrasound scanning is cheap, easy to perform, non-invasive and easily repeatable, and it has become a routine procedure in neonatal intensive care, and in particular in all the infants who are at risk for brain lesions.

Many studies have been performed in preterm infants and these have provided important information on the incidence and evolution of cerebral lesions and their relation with gestational age. ${ }^{1-4}$ Cranial ultrasonography has also been widely used in full term infants, but mainly in those who are at risk of brain lesions, such as those with birth asphyxia or abnormal neurological signs..$^{3-9}$

\section{Methods}

The infants described in this study are part of an ongoing project investigating antenatal, perinatal, and postnatal findings in a population of infants regarded as normal by the obstetric and paediatric staff, and admitted soon after birth in the postnatal ward. The project has been approved by the Research Ethical Committee of the Royal Postgraduate Medical School. As part of this study mothers of infants admitted to the postnatal ward in the Queen Charlotte and Chelsea Hospital were asked to volunteer for a neurological examination and a cranial ultrasound scan to be performed on their infant. Mothers were approached while inpatients and their consent requested after the project had been explained to them. An information sheet was also available.

Data were collected on two or three days a week over a period of six months. On those days the examiners tried to examine all the infants on the ward. The only inclusion criteria were that: the infants were admitted soon after birth on the postnatal ward; and their age was between 6 and 48 hours. The age of the infant was obtained by the ward admission book and was the only information available at the time of examination.

Ultrasound scans were performed with an Advanced Technology Laboratory (ATL) mark IV sector scanner, using a 5 and $7.5 \mathrm{MHz}$ 
Table 2 Details of ultrasound and clinical neurological findings

\begin{tabular}{|c|c|c|c|c|c|c|c|c|}
\hline & \multicolumn{8}{|c|}{ Neurological examination } \\
\hline & $\begin{array}{l}\text { Normal } \\
(n=134)\end{array}$ & $\begin{array}{l}\text { Abnormal } \\
\text { tone }(n=13)\end{array}$ & $\begin{array}{l}\text { Abnormal } \\
\text { alert }(n=1)\end{array}$ & $\begin{array}{l}\text { Tremors } \\
(n=7)\end{array}$ & $\begin{array}{l}\text { Abnormal tone } \\
\text { and alert } \\
(n=10)\end{array}$ & $\begin{array}{l}\text { Abnormal tone } \\
\text { and tremors } \\
(n=4)\end{array}$ & $\begin{array}{l}\text { Abnormal alert and } \\
\text { tremors }(n=2)\end{array}$ & $\begin{array}{l}\text { All abnormal } \\
(n=6)\end{array}$ \\
\hline Normal ultrasound $(n=128)$ & 113 & 3 & & 5 & 4 & 1 & & 2 \\
\hline Full choroid $(n=14)$ & 10 & 1 & 1 & 1 & & & 1 & \\
\hline Periventricular densities $(\mathrm{n}=12)$ & 4 & 4 & & & 2 & 1 & & 1 \\
\hline Thalamic densities $(n=3)$ & & & & & 2 & 1 & & \\
\hline Asymmetrical ventricles $(n=6)$ & 2 & 1 & & & 1 & 1 & 1 & \\
\hline IVH $(n=9)$ & 1 & 4 & & 1 & 1 & & & 2 \\
\hline Petecchial WMH $(\mathrm{n}=1)$ & & & & & & & & 1 \\
\hline Arachnoid, parameters, choroid cysts $(n=4)$ & 4 & & & & & & & \\
\hline
\end{tabular}

probe. The scans were assessed for normal anatomy, ventricular size, and evidence of focal or diffuse increased echogenicity in the cerebral hemispheres and basal ganglia. Hard copies were obtained with a Polaroid camera in standard views.

Neurological examination was performed and recorded using a modified version of a standardised proforma ${ }^{10}$ evaluating posture, movements, tone, reflexes and some aspects of behaviour. All the infants also underwent an assessment of gestational age. ${ }^{11}$

Both ultrasound scans and clinical examination were performed by two examiners (LD and $\mathrm{EM}$ ). The infants were examined in their cot on the postnatal ward. Ultrasound scans were always performed after the neurological examination and usually after all the clinical examinations for that day had been completed.
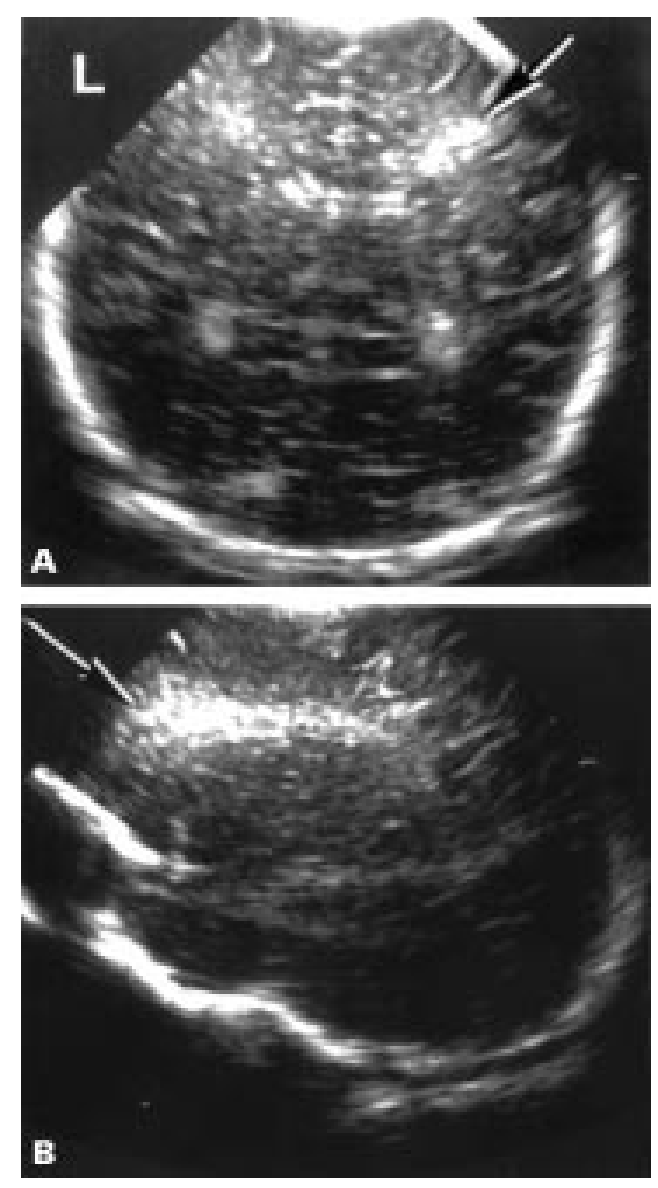

Figure 1 Coronal (A) and parasagittal (B) sections (7.5 $M H Z$ ). Note right periventricular density is more marked anteriorly.
Only in a limited number of cases were ultrasound scans and clinical examination performed by the same examiner. All the scans were reviewed by both examiners independently on the same day as they were performed. A third examiner (FC), unaware of the clinical results and of the interpretation of the scans, reviewed and classified the scans after the collection of the data had been completed. Only in one case was the third reviewer's classification discordant with the diagnosis made on the day the scan was performed.

Antenatal and perinatal clinical details were obtained from the obstetric notes. Obstetric notes were always examined only after the clinical examination and ultrasonography had been performed, either on the same day or within a week of the examinations. Cardiotocograms (CTG) were available in 154 of the 177 infants studied and were classified accord-
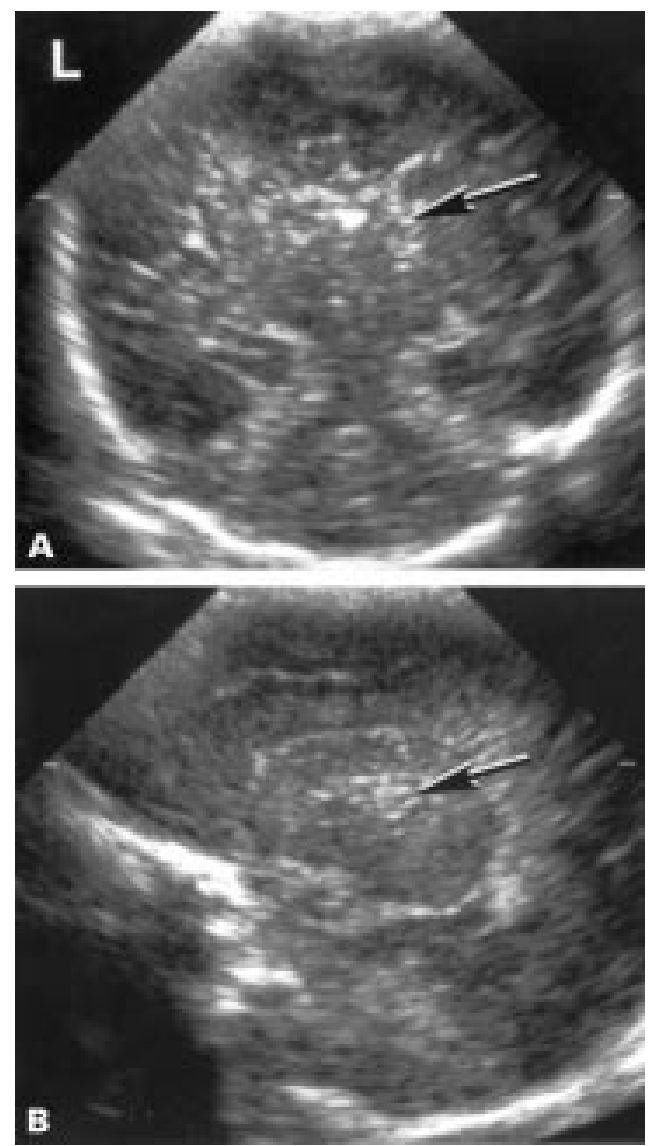

Figure 2 Coronal $(A)$ and parasagittal (B) sections (7.5 $M H Z)$. Note left thalamic density. 

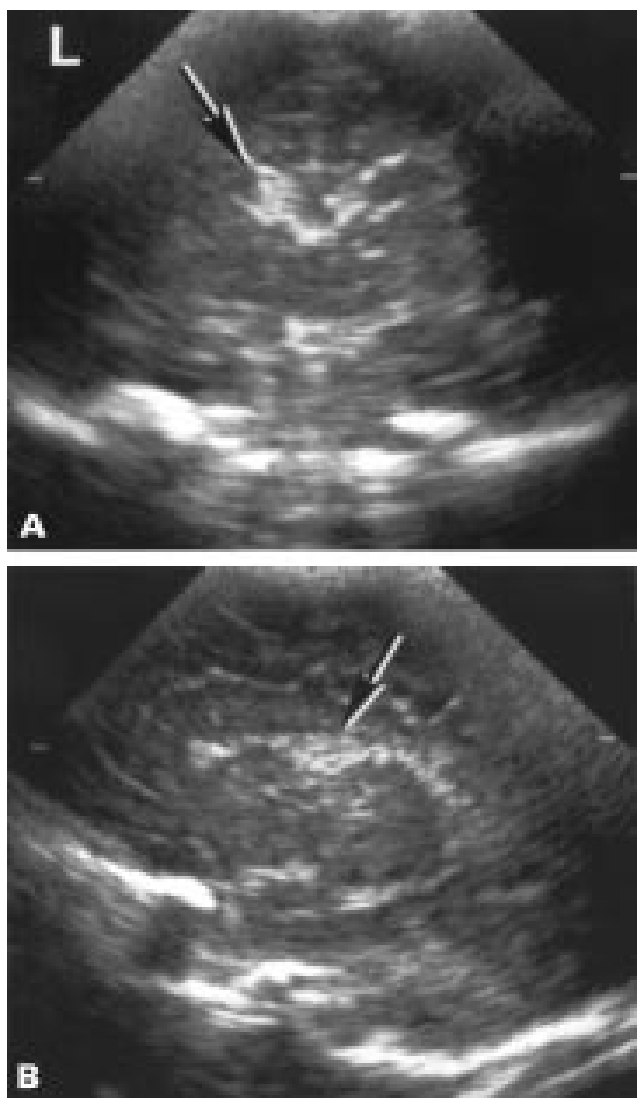

Figure 3 Coronal $(A)$ and parasagittal (B) sections (7.5 $\mathrm{MHz}$. Note left grade 1 intraventricular haemorrhage (arrows).

ing to the description reported in the maternal notes and partograms. Decelerations $(<90)$, tachycardia $(>160)$, or loss of variability were classified as abnormal when continuous and showing no or slow recovery.

Non-parametric statistic ( $\chi^{2}$ test) was used for the analysis of the results.

\section{Results}

Two hundred and forty nine out of 253 mothers asked to volunteer to the project agreed to the clinical neurological examination. An ultrasound scan was not performed in 72 of 250 either because parents did not give their consent $(n=47)$ or because the scanner was not available before the infants were discharged $(n=25)$. One hundred and seventy seven had a neurological examination and an ultrasound scan. Their ages ranged between 36.3 and 42 weeks (mean 39.8).

Parity, maternal age, and mode of delivery in our cohort were similar to those of the global population born in the same hospital in the six months preceding this study (table 1).

Twenty four infants had a history of antenatal bleeding, 13 of mildly raised mater-
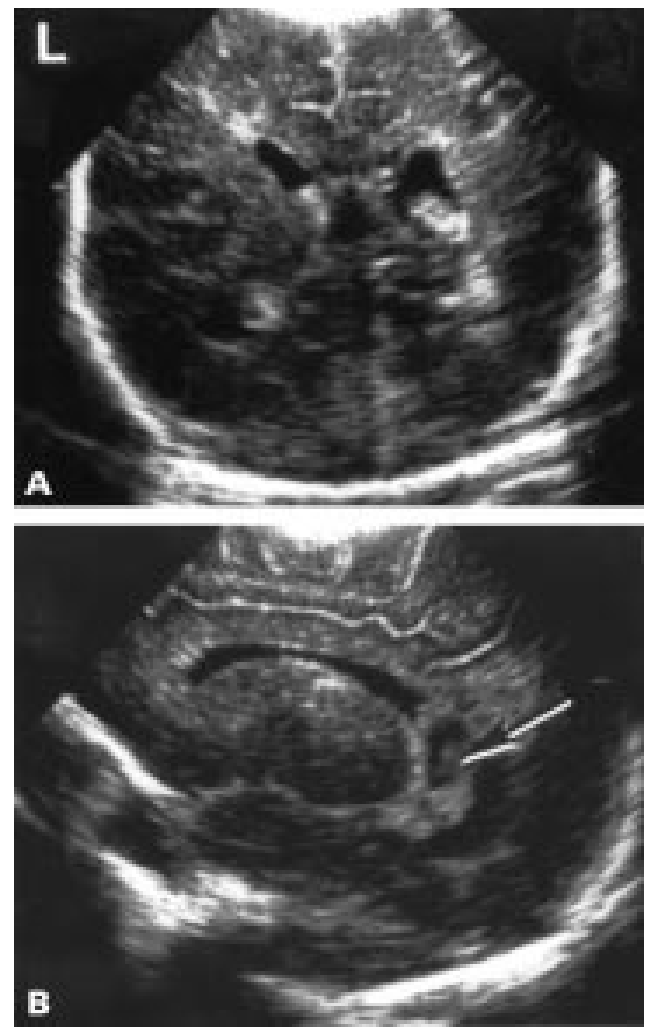

Figure 4 Coronal (A) and parasagittal (B) sections (7.5 $\mathrm{MHz}$ ). Note bilateral intraventricular haemorrhage on coronal section with bilaterl ventricular dilatation $(A)$ and clot in left ventricle (B) (arrows).

nal blood pressure which did not require any treatment, 10 of in utero documented growth retardation (IUGR) and eight of reduced fetal movements. Maternal drug addiction, hypoparathyroidism, and hyperthyroidism were a factor in three other pregnancies.

Nine infants had grade 1, 16 grade 2, and three grade 3 meconium; 19 had an abnormal CTG. Three infants had an Apgar score below 8 at 5 minutes, and two of these also had a cord $\mathrm{pH}$ below 7.2.

Completely normal scans were found in 128 of the 177 infants who had an ultrasound scan. Some changes were found in the remaining 49: 12 showed periventricular (fig 1) and three unilateral thalamic densities (fig 2). Ten infants showed minor changes which were likely to be the sequelae of antenatal haemorrhages, such as focal asymmetrical ventricular dilatation (6) and paramedian or choroid cysts.(4) Another 10 infants showed haemorrhagic changes. Nine of these had intraventricular haemorrhage (figs 3 and 4) which were classified according to de Vries et $a l^{12}$ (four grade 1 , four grade $2 \mathrm{a}$, and one grade $2 b$ ) and haemorrhage localised in the white matter in the remaining one. The infant with grade $2 \mathrm{~b}$ haemorrhage also showed

Table 3 Ultrasound findings and antenatal risk factors: values are number (\%)

\begin{tabular}{|c|c|c|c|c|c|c|c|c|c|c|c|c|}
\hline & \multicolumn{3}{|c|}{ Maternal age } & \multicolumn{2}{|l|}{ Parity } & \multicolumn{7}{|c|}{ Abnormal events } \\
\hline & $\begin{array}{l}<30 \\
(n=73)\end{array}$ & $\begin{array}{l}30-35 \\
(n=59)\end{array}$ & $\begin{array}{l}>35 \\
(n=45)\end{array}$ & $\begin{array}{l}\text { Primipara } \\
(n=93)\end{array}$ & $\begin{array}{l}\text { aMultipara } \\
(n=84)\end{array}$ & $\begin{array}{l}\text { Bleed } \\
(n=24)\end{array}$ & $\begin{array}{l}\text { Blood pressure } \\
(n=13)\end{array}$ & $\begin{array}{l}I U G R \\
(n=10)\end{array}$ & $\begin{array}{l}R F M \\
(n=6)\end{array}$ & $\begin{array}{l}\text { Other } \\
(n=3)\end{array}$ & $\begin{array}{l}\text { Global abnormal } \\
\text { events }(n=56)\end{array}$ & $\begin{array}{l}\text { No abnormality } \\
(n=121)\end{array}$ \\
\hline Normal ultrasound & $44(61)$ & $48(81)$ & $36(80)$ & $61(66)$ & $67(79)$ & $18(75)$ & $8(62)$ & $3(30)$ & $3(50)$ & $3(100)$ & $35(62)$ & $93(77)$ \\
\hline Full choroid & $9(12)$ & $3(5)$ & $2(4)$ & $9(10)$ & $5(6)$ & $1(4)$ & $3(23)$ & 0 & $1(17)$ & 0 & $5(9)$ & $9(7)$ \\
\hline Abnormal ultrasound & $20(27)$ & $8(14)$ & $7(16)$ & $23(24)$ & $12(15)$ & $5(21)$ & $2(15)$ & $7(70)$ & $2(35)$ & 0 & $16(29)$ & $19(16)$ \\
\hline
\end{tabular}


Table 4 Ultrasound findings and perinatal risk factors: values are number (\%)

\begin{tabular}{|c|c|c|c|c|c|c|c|c|c|c|}
\hline & \multicolumn{2}{|c|}{$C T G\left(n=154^{\star}\right)$} & \multicolumn{3}{|l|}{ Meconium } & \multicolumn{5}{|c|}{ Mode of delivery } \\
\hline & $\begin{array}{l}\text { Normal } \\
(n=135)\end{array}$ & $\begin{array}{l}\text { Abnormal } \\
(n=19)\end{array}$ & $\begin{array}{l}\text { No } \\
(n=149)\end{array}$ & $\begin{array}{l}\text { Grade } 1 \\
(n=9)\end{array}$ & $\begin{array}{l}\text { Grade } 2 / 3 \\
(n=19)\end{array}$ & $\begin{array}{l}S V D \\
(n=101)\end{array}$ & $\begin{array}{l}\text { Elective CS } \\
(n=21)\end{array}$ & $\begin{array}{l}\text { Ventouse } \\
(n=25)\end{array}$ & $\begin{array}{l}\text { Forceps } \\
(n=13)\end{array}$ & $\begin{array}{l}\text { Emergency } \\
\text { caesarean }(n=17)\end{array}$ \\
\hline Normal ultrasound & $103(78)$ & $14(76)$ & $111(74)$ & $6(67)$ & $11(59)$ & $75(74)$ & $13(62)$ & $18(72)$ & $10(77)$ & $12(71)$ \\
\hline Full choroid & $10(7)$ & $1(6)$ & $13(9)$ & 0 & $1(5)$ & $10(10)$ & $2(10)$ & $2(8)$ & 0 & 0 \\
\hline Abnormal ultrasound & $22(15)$ & $4(18)$ & $25(17)$ & $3(33)$ & $7(37)$ & $16(16)$ & $6(28)$ & $5(20)$ & $3(23)$ & $5(29)$ \\
\hline
\end{tabular}

periventricular densities. An unusually full choroid was found in 14 infants and classified separately. Table 2 shows the details of the ultrasound findings.

Normal neurological examination was found in 134 of the 177 infants studied. The remaining 43 all showed some deviant neurological patterns: 13 showed abnormal tone, one abnormal alertness, seven had tremors and 22 had some combination of the above. Table 2 gives details of the neurological examinations.

Table 3 gives details of the correlation between ultrasound findings and antenatal factors. There was no significant relation between ultrasound abnormality and either maternal age $(\mathrm{p}=0.063)$ or parity $(\mathrm{p}=1.47)$.

Although there was a tendency for infants with adverse antenatal factors to have abnormal scans than those without, the association between ultrasound scans and overall abnormal events in pregnancy was not significant $(p=0.053)$. The numbers were too small for meaningful separate analysis, but most of the antenatal events, with the exception of IUGR, did not show any consistent association with abnormal ultrasound findings. IUGR diagnosed in utero was the only antenatal factor more consistently associated with abnormal ultrasound scans, as seven out of the 10 infants with IUGR had abnormal neonatal scans.

Table 4 gives details of the correlation between ultrasound findings and perinatal factors. There was no significant association between ultrasound abnormalities and the presence of markers of perinatal distress such as CTG abnormalities or presence of meconium 2 and 3. Similarly, there was no correlation between ultrasound abnormalities and mode of delivery $(p=0.113)$.

Only three infants in our cohort had Apgar scores less than 5 at 1 minute or less than 8 at 5 minutes. All three had an abnormal ultrasound scan.

Two of the three infants had cord $\mathrm{pH}$ below 7.2; both had abnormal ultrasound scans.

Table 5 shows details of the correlation between ultrasound findings and neurological signs. The association was highly significant $(\mathrm{p}<.0001)$.

Table 5 Correlation between ultrasound and clinical neurological abnormalities ( $\chi^{2}$ test). Values are number (\%)

\begin{tabular}{llll}
\hline & \multicolumn{2}{c}{ Neurological examination } & \\
\cline { 2 - 3 } & $\begin{array}{l}\text { Normal } \\
(n=133)\end{array}$ & $\begin{array}{l}\text { Deviant patterns } \\
(n=43)\end{array}$ & $\chi^{2}$ test \\
\hline $\begin{array}{c}\text { Normal } \\
\text { ultrasound }\end{array}$ & $113(85)$ & $15(35)$ & \\
$\begin{array}{c}\text { Full choroid } \\
\text { Abnormal } \\
\text { ultrasound }\end{array}$ & $10(7)$ & $\begin{array}{l}4(9) \\
24(56)\end{array}$ & $\mathrm{p}<0.0001$ \\
\hline
\end{tabular}

\section{Discussion}

Only a few studies have previously assessed cranial ultrasound in clinically unselected infants. ${ }^{13-18}$ In these studies intracranial haemorrhages were the most commonly reported abnormalities (with an incidence ranging between 2.7 and $5.5 \%$ ). Lesions diagnosed as possible sequelae to antenatal haemorrhages were present in 3 to $4 \%$. One of these studies ${ }^{18}$ also reported morphological aberrations in an additional $3 \%$ of the population, with an overall incidence of abnormal findings of $9 \%$.

The incidence of both intracranial haemorrhages $(6 \%)$ and possible sequelae of antenatal haemorrhages $(6 \%)$ in our cohort was only slightly higher than in the previous studies. We also found that 14 children (8\%) showed an unusually full choroid plexus. As we found it difficult to decide whether these were normal variants or small choroid haemorrhages, these infants were considered separately in order to avoid overestimation of the incidence of abnormal scans. Interestingly, their neurological findings were much closer to those of the infants with abnormal ultrasound scans than to those with normal scans. In addition, periventricular and thalamic densities, which have not bee reported before, were observed in $8 \%$, resulting in an overall incidence of $20 \%$ of ultrasound abnormalities.

The difference between our findings and previous studies can be explained by several factors. Our higher incidence of lesions can partly be attributed to the type of population admitted to the hospital - an obstetric tertiary care centre. As we were interested in evaluating the incidence of ultrasound abnormalities in an unselected population of infants admitted in the postnatal ward who were classified as normal and ready to be discharged, we did not exclude, unlike the previous studies, infants below 37 weeks or those with mild perinatal distress or antenatal problems. Nevertheless, although these seem the most likely reason for the difference observed, none of the markers of perinatal or antenatal distress evaluated showed any consistent association with abnormal ultrasound findings. Only infants with an intrauterine diagnosis of IUGR were more frequently associated with ultrasound abnormalities.

Even excluding the infants with antenatal and/or perinatal factors from our cohort, however, the incidence of abnormal ultrasound scans is still significantly higher $(15.8 \%)$ than studies have reported before. We feel that the higher incidence of abnormal ultrasound findings is probably due to the presence of periventricular and thalamic densities that have not been described in previous studies. The 
absence of these lesions in the publications in the early 1980s may be due to the fact that there was less awareness of these lesions and that they were probably more difficult to detect with the generation of scanners available at that time, ${ }^{14-17}$ although these have not been mentioned in a more recent publication. ${ }^{18}$

Ultrasound abnormalities were significantly associated with deviant patterns on clinical neurological examination $(p=<0.0001)$. Severe neurological abnormalities, however, were only seen in three cases, while only mild signs such as decreased tone or reduced alertness were found in all the others. Although these patterns were not severe enough to attract the attention of parents or midwives, they could be observed easily by a paediatrician on a structured neurological examination.

Our results suggest that ultrasound abnormalities in apparently well neonates may be more common than previously reported and that lesions which could be ischaemic such as flare densities can be observed even in the absence of any antenatal or perinatal risk factors. The prognostic importance of these findings is not completely clear. Previous studies in preterm infants with similar lesions have shown that these infants do not show severe motor or cognitive impairment. ${ }^{19-23}$ While small haemorrhages are rarely associated with sequelae, however, it has also been reported that persistent periventricular densities often result in minor motor or perceptual difficulties later on. ${ }^{19-23}$ The same might apply to these infants.

1 Pape KE, Blackwell RJ, Cusick G, et al. Ultrasound detection of brain damage in preterm infants. Lancet 1979 i: $1261-74$.

2 Levene MI, Wigglesworth JS, Dubowitz V. Cerebral structure and intraventricular haemorrhage in the neonate. A real time ultrasound study. Arch Dis Child 1981;56:416-24.

3 Rennie JM. Neonatal cerebral ultrasound. Cambridge: Cambridge University Press, 1997.

4 Govaert P, de Vries L. An atlas of neonatal brain sonography. Clinics in Developmental Medicine, 141-2. London: McKeith Press, 1996.
5 Rollins NK, Morris MC, Evans D, Perlmann JM. The role of of early MR in the evaluation of the term
seizures. Am $\mathcal{F}$ Neurol Radiol 1993;15:239-48.

6 Eken P, Jansen GH, Groenendaal F, Rademaker KJ, de Vries LS. Intracranial lesions in the full term with hypoxic-ischaemic lesions. Neuropediatrics 1994;24:301-7.

7 Mercuri E, Cowan F, Rutherford M, Acolet D, Pennock J, Dubowitz L. Ischaemic and haemorrhagic brain lesions in newborns with seizures and normal Apgar scores. Arch Dis Child 1995;73:F67-F74.

8 Rutherford MA, Pennock JM, Dubowitz LMS. Hypoxicischaemic encephalopathy : a comparison of cranial ultrasound and magnetic resonance imaging with outcome. Dev Med Child Neurol 1994;35:813-25.

9 Govaert P. Cranial haemorrhage in the term newborn infant. Clinics in Developmental Medicine, 129. London: McKeith Press, 1993.

10 Dubowitz L, Dubowitz V. The Neurological assessment of the preterm and full term newborn infants. Clinics in Developmental Medicine, 79. London: SIMP, 1981.

11 Dubowitz LMS, Dubowitz V, Goldberg C. Clinical assessment of gestational age in the newborn infant. $f$ Pediatr 1970;77:1.

12 de Vries LS, Dubowitz LMS, Dubowitz V, et al. Predictive value of cranial ultrasound: a rappraisal. Lancet 1985; ii: $137-40$.

13 Guekos-Thoni U, Bolthauser E, Mieth D, et al. Intracranial haemorrhage in the term infant confirmed by computed tomography. Helv Pediatr Acta 1980;35:531-44.

14 Guekos-Thoni U, Bolthauser E, Willi UB. Intraventricular hemorrhage in full-term neonates. Dev Med Child Neurol 1982;24:704-5.

15 Scher NS, Wright FS, Lockman LA, et al. Intraventricular hemorrhage in the full-term neonate. Arch Neurol 1982;39:769-83.

16 Shen EY, Huang FY. Subependymal cysts in normal neonates. Arch Dis Child 1985;60: 1072-4.

17 Hayden CK, Shattuck KE, Richardson CJ, Ahrendt DK, House R, Swiscuk LE. Subependymal germinal matrix hemorrhage in full-term neonates. Pediatrics 1985;75:714-

18 Heibel M, Heber R, Bechinger D, Kornhuber HH. Early diagnosis of perinatal cerebral lesions in apparently normal full-term newborns by ultrasound of the brain. Neuroradiology 1993;35: 85-91.

19 Fawer CL, Calame A. Significance of ultrasound appearances in the neurological development and cognitive abilities of preterm infants at 5 years. Eur $\mathcal{f}$ Pediatr 1991;150:512-20.

20 Roth SC, Baudin J, Mc Cormick DC, et al. Relation between ultrasound appearance of the brain of very preterm infants and neurodevelopmental impairm

21 Marlow N, Roberts BL, Cook RWI. Motor skills in extremely low birth weight children at the age of 6 years. Arch Dis Child 1989;64:839-47.

22 Levene M, Dowling S, Graham M, Fogelman K, Galton M, Philips M. Impaired motor function (clumsiness) in 5 year old children: correlation with neonatal ultrasound. Arch Dis Child 1992; 67:687-90

23 Jongmans M, Mercuri E, de Vries L, Dubowitz L, Henderson S. Minor neurological signs in preterm infants at school age. Arch Dis Child 1997;76: F9-14. 